\title{
A Study of Evapotranspiration from a Douglas Fir Forest Using the Energy Balance Approach
}

\author{
K. G. MeNaughton and T. A. Black \\ Department of Soil Science, University of British Columbia \\ Vancouver, British Columbia, Canada
}

\begin{abstract}
Energy balance measurements of evapotranspiration from a young Douglas fir forest are reported for a period of 18 days in July 1970 when soil water was not limiting. Peak daily evapotranspiration rates characteristically occurred 2-3 hours after solar noon, and evapotranspiration showed a short-term independence from net radiation. This behavior is interpreted as being a consequence of the large forest roughness. Daily evapotranspiration and net radiation were, however, well correlated. Values of surface diffusion resistance calculated from Monteith's combination formula are presented. Daytime values showed significant day-to-day differences, and an attempt to define a potential eyapotranspiration rate by assuming a constant daytime surface resistance was not suecessful. Comparison of evapotranspiration measurements with a potential evaporation formula for wet surfaces developed by Priestley and Taylor suggests that evaporation of intercepted water proceeds $20 \%$ more rapidly than evapotranspiration from the nonwetted canopy.
\end{abstract}

In July and August, 1970, energy balance/ Bowen ratio measurements of evapotranspiration from a young Douglas fir forest were made as part of a hydrologic balance experiment on a site in the University of British Columbia (UBC) Research Forest.

Examination of the energy balances computed from the measurements reveals several clear patterns in the results. This paper presents the results for the initial 18-day period of the experiment and discusses these patterns and some of the implications of the results. As a basis for interpreting the results, Monteith's [1965] canopy transpiration model has been used for part of the analysis.

\section{Monteith's Equation}

Penman [1948] has shown that energy balance and aerodynamic equations for evaporation can be combined to give an expression for evaporation from extensive wet surfaces in terms of easily measurable parameters. Businger [1956] has developed a rational expression based on measured wind profiles for the original empirical wind function.

The accuracy of the resulting combination formula for calculating evaporation from wet surfaces with small roughness lengths has been

Copyright (c) 1973 by the American Geophysical Union established by the experimental work of Van Bavel [1966]. In modern resistance términology this expression can be written as

$$
\begin{array}{r}
E_{0}=(1 / L)[s /(s+\gamma)]\left(R_{N}-G-M\right) \\
+\left[\rho c_{p}\left(e_{z}^{*}-e_{z}\right)\right] /\left[(s+\gamma) r_{a} L\right]
\end{array}
$$

where the aerodynamic resistance $r_{a}$ is given by

$$
r_{a}=u_{z} / u_{*}^{2}
$$

when a similarity is assumed between the transfer coefficients for momentum, heat, and water vapor and when the virtual sink for momentum is taken to be also a virtual source for heat and water vapor. The quantity $E_{0}$, defined by (1), will be called the free evaporation rate in this paper.

Monteith [1965] introduced the effect of diffusive resistance to vapor flow of the stomata of the vegetative canopy by considering the canopy as a single extensive isothermal leaf. In his model, transpiration from this leaf is expressed as

$$
E=\left(\rho c_{p} / L \gamma\right)\left[\left(e_{0}^{*}-e_{0}\right) / r_{\bullet}\right]
$$

where the subscript zero refers to values at the canopy surface obtained by extrapolating the temperature and humidity profiles down to $\left(z_{0}+D\right)$. Following a procedure similar to that 
of Penman [1948], Monteith derived the expression for transpiration

$$
E=\frac{E_{0}}{1+[\gamma /(s+\gamma)]\left(r_{s} / r_{a}\right)}
$$

where the surface resistance $r_{s}$ is formally identified as the resistance of all the stomata of the leaves of the canopy acting in parallel.

Total evapotranspiration can be considered as entirely transpiration with small error for forests when intercepted water is not present, since soil evaporation has been found to be small by many workers [e.g., Rutter, 1966].

\section{Surface and Aerodynamic Resistances}

The one-layer model is a considerable simplification of real plant canopies and has attracted strong criticism [Phillip, 1963, 1966; Tanner, 1963; Tainner and Fuchs, 1968]. These criticisms arise from the observation that the simple one-layer model ignores leaf boundary layer diffusion resistances and aerodynamic diffusion resistances between different levels of the canopy. An examination shows that transpiration from each individual leaf surface can be summed to produce an expression for transpiration from the whole canopy that is in the form of (3) only under the assumption that these resistances are indeed negligible. In general, the surface resistance cannot be rigorously identified with the stomatal resistance of all the leaf surfaces acting in parallel, and such interpretation must be justified by examining the assumptions for each canopy studied.

From the results of Rutter [1967] for a Scots pine plantation it can be seen that stomatal resistances were large in comparison with the aerodynamic and boundary layer resistances within the canopy. There is some expectation, therefore, that surface resistance may be closely related to stomatal resistance in that case and, by implication, also in the present analysis.

Good wind profile data for calculating $r_{a}$ are frequently unavailable. For this reason a consideration of the errors introduced into the values of $E$ calculated from (4) caused by an error of estimate in $r_{a}$ is appropriate here.

An error formula can be derived by differentiating (4) with respect to $r_{a}$ and then integrating over the range of error from $r_{a}$ to $r_{a}+$ $\Delta r_{a}$. Thus

$$
\begin{aligned}
\Delta E / E= & (s \beta-\gamma) \Delta r_{a} \\
& \div\left[(s+\gamma)\left(r_{a}+\Delta r_{a}\right)+r_{s} \gamma\right]
\end{aligned}
$$

where the Bowen ratio $\beta$ has been introduced for convenience. It can be seen that $E$ is independent of $r_{a}$ when $\beta=\gamma / s$, as has been noted previously by Monteith [1965].

Anticipating the results of this paper, for a forest we can take $r_{a} \approx 5$ sec $\mathrm{m}^{-1}, r_{s} \approx 75$ sec $\mathrm{m}^{-1}$, and $\beta \approx 1$ and assume that $T=18^{\circ} \mathrm{C}$ and $s=1.29 \mathrm{mb} \mathrm{K}^{-1}$. An overestimate of $r_{a}$ by $50 \%$ introduces only a $2 \frac{1}{2} \%$ overestimate in the calculated value of $E$. Further, if we let $r_{a}$ approach zero, (4) becomes

$$
E=\left(\rho c_{p} / L \gamma r_{s}\right)\left(e_{z}^{*}-e_{z}\right)
$$

with only $5 \%$ underestimate. This result indicates that a forest transpiring in accordance with (4) is little affected by wind speed and that radiation is important indirectly through its effect on stomatal resistance and on temperature and therefore on vapor pressure deficit. Both stomatal resistance and vapor pressure deficit are expected to show a slow response to changes in radiation, and therefore (6) predicts poor correlation between changes in transpiration and radiation over periods of less than a few hours. In addition, (6) suggests that diurnal trends in the evapotranspiration rate will tend to follow the trend of the atmospheric vapor pressure deficit if the daytime trend of stomatal resistance is not too large. Stewart and Thom [1973] have also examined forest transpiration and have independently derived a relationship (their equation 32 ) that is easily shown to be equivalent to (6).

Hinckley and Scott [1971] have found no significant correlation between solar radiation and sap velocity in Douglas fir trees under conditions of high atmospheric demand. Measurements of transpiration by Parker [1957] made by quick-weighing excised leaves of opengrown oak and white pine show na short-term response to changes in sunlight measured with a pyrheliometer. Comparisons of transpiration estimated from sap velocity with wind speed and light intensity made by Ladefoged [1963] showed little correlation and also support this conclusion. Ladefoged found, on the other hand, a dependence on relative humidity. Inspection of his Figures 10-13 suggests a strong correla- 
tion between vapor pressure deficit and transpiration in agreement with (6).

In this paper $r_{\mathrm{s}}$ is computed from Monteith's equation (4). The effect of an error in $r_{a}$ on the value of $r$, calculated from (4) can be found by transforming (4) to make $r$, the subject of the equation and then differentiating with respect to $r_{a}$. Integration of the resulting expression over the range of error from $r_{a}$ to $r_{a}+\Delta r_{a}$ then gives

$$
\Delta r_{s}=[(\beta s / \gamma)-1] \Delta r_{a}
$$

When the values above are substituted, (7) shows that a $50 \%$ error in $r_{a}$ introduces only a $3 \%$ error into the value of $r_{s}$.

Cowan [1968] and Thom [1972] have examined the assumption of similarity of the aerodynamic diffusion resistance for momentum and the aerodynamic diffusion resistances for heat and vapor. Both investigators consider that the assumption of similarity may not be appropriate for exchange within canopies. Stewart and Thom [1973] have included a discussion of this problem for a forest. However, in view of the insensitivity of forest transpiration and surface resistance values calculated from (4) to errors in $r_{a}$, this aspect will not be examined here. In calculating $r_{a}$ for forests from (4), the major uncertainty will usually be caused by errors in the measured values of transpiration.

\section{Experimental Site}

The experimental site was located in a Douglas fir plantation growing on a glacial outwash terrace in the UBC Research Forest at Haney, British Columbia, at an altitude of 250 meters. The plantation was of a fairly uniform height of about 7.8 meters with some differences in stand spacing in the southern section. Fetch was between 200 and 400 meters in all directions from NNE through E-SW but was limited in the remaining directions by a river cutting adjacent to the site. The plantation area sloped down at about 5\% towards the southwest. Beyond the plantation, about 200 meters to the east, was older regrowth forest about 25 meters tall on a slope of about $10 \%$ grading upward to the east. Land in all directions was predominantly forest covered for more than $2 \mathrm{~km}$. It is unlikely that advected energy had any significant effect on the evaporation processes near the experimental tower.
Measurements of net radiation, wind speed at 8.75 meters, and wet and dry bulb temperatures at 8.1 and 9.1 meters, respectively [Black and McNaughton, 1971], were made with instruments supported above the canopy on a meteorological tower. A thermometer and a dewcell were located in a small slatted screen 3 meters above the forest floor. Two soil heat flux plates were placed at a depth of $5 \mathrm{~cm}$ in the soil, and the mean temperature of the surface 5-cm layer was determined with two integrating thermometers. Samples of the top $\mathbf{5}$ $\mathrm{cm}$ of the soil were collected daily for determination of the heat capacity of the layer. A tensiometer-transducer system was used to monitor soil water potential at depths from 30 to $150 \mathrm{~cm}$ at $30-\mathrm{cm}$ intervals. The tree root zone extended to a depth of $60 \mathrm{~cm}$. Visual observation of a wind vane at the top of the tower indicated that wind was predominantly from the southerly quarter during the daytime. At night a valley wind system produced northeasterly winds.

During the month of June preceding the experiment, $9.4 \mathrm{~cm}$ of rain were recorded at a permanent weather station about 400 meters from the experimental site. Of this total, $6 \mathrm{~cm}$ were recorded during the period June 26-29. No rain fell between June 29 and the commencement of detailed measurements.

Sites with satisfactory fetch for micrometeorological measurements are rare in the mountainous Canadian west coast region. In spite of the nonideal conditions for the present study, it is felt that the older regrowth forest beyond the plantation boundary should have had very similar surface temperature and fluxes of heat and vapor and that little adjustment of the boundary layer properties would have been necessary.

\section{Results and Discussion}

Energy balance. From the data collected during the period July 8-25, 1970, average values of the terms of the familiar energy balance equation

$$
R_{N}=H+L E+G+M
$$

were evaluated for each half hour. Photosynthetic energy storage rate and horizontal energy flux divergence terms were assumed negligible. 
Soil heat flux was calculated by correcting the 5-cm flux plate reading for heat storage changes in the top 5-cm layer. It was not passible to evaluate the canopy volume heat storage rate term $M$ with precision, and values used in this analysis are estimated from the air temperature and vapor pressure within and above the canopy and estimates of biomass volume and heat capacity of the trees. In the results the quantity $\left(R_{N}-G-M\right)$ usually decreased to zero in the evening after the wet bulb gradient diminished to zero, and it was thus indicated that the rate of heat released by the canopy was larger than the calculated value at that time. A method used to estimate the error in the daily values of evapotranspiration due to uncertainty in the values of $G$ and $M$ suggests that errors in the daily values from this source are negligible [Black and $M c$ Naughton, 1972].

The Bowen ratio technique was used to partition the available energy between $H$ and $L E$. An example of the energy balance for one day from this period has been presented previously [Black and McNaughton, 1971]. (Since the dry bulb temperature gradient above the forest is small, correction for the adiabatic lapse rate $\left(-0.01^{\circ} \mathrm{C} / \mathrm{m}\right)$ is significant and has been applied to the calculations for the present and preceding papers [Black and McNaughton, 1971, 1972]. Equation 1 of Black and McNaugton [1971] is suitable only for error estimation.) When the Bowen ratio is near -1 , large errors in the computed fluxes may occur. In this study values of the Bowen ratio in the range $-1.5<\beta<0.5$ were rare, except for two or three values about 1800 PST each afternoon when total energy exchange was small. Little error has been introduced in smoothing values at these times by eye before making the daily (24 hour) totals of evapotranspiration reported in this paper. Results for selected days presented in Figures 1 and 2 are unsmoothed.

Summation of possible error from all sources except that introduced by ignoring photosynthesis and horizontal divergence terms indicates that individual values of $E$ through most of the day have an uncertainty of $20 \%$. However, consistency of the results indicates that random errors are usually less. Possible systematic error 1n net radiation measurement due to calibration $\left(2 \frac{1}{2} \%\right)$ and sampling $(3 \%)$ [Federer,
$1968]$ and error introduced by ignoring photosynthetic energy storage $(<5 \%)$ do not affect the comparisons made in this paper. Errors due to horizontal flux divergence are not amenable to this type of analysis but do not appear to be large. It is expected that the 24-hour totals of evapotranspiration are accurate to within $15 \%$.

Energy balance results were found to show a consistent pattern with two distinctive features that differentiate them from typical balances for low agricultural crops. Short-term fluctuations in radiation did not produce corresponding proportional changes in the latent heat flux. An example is shown in Figure 1 for a partly cloudy day, July 23. This pattern may be contrasted with, for example, an energy balance of irrigated alfalfa-brome grass on a partly cloudy day measured by Tanner and Pelton [1960], where changes in net radiation and latent heat flux are strongly coupled. Secondly, peak evapotranspiration rates consistently occurred 2-3 hours after solar noon. This behavior is shown in the energy balances presented for July 8, 10, 15, and 18 in Figure 2. Gay [1972] has reported a nearly identical pattern for a clear July day energy balance of a taller Douglas fir forest at Cedar River, Washington. Fritschen and Doraiswamy [1973] have made lysimetric measurements of evapotranspiration from a single Douglas fir tree in early May 1972 on the site used by Gay. Their results also show that the daily evapotranspiration maximums occur several hours after the net radiation maximums. These results show that forest evapotranspiration is not directly 'driven' by net radiation in accordance with the approximation of Monteith's equation for rough surfaces (6).

Surface resistance. When the results of the measurements and calculations described above were taken, only $r_{a}$ remained to be evaluated to solve (4) for $r_{s}$.

Wind profiles suitable for use in calculating aerodynamic resistance $r_{a}$ were not measured. Wind profiles have been estimated from wind at one height and temperature gradient measurements using diabatic profile theory and assumed values of surface roughness and displacement height [Black and McNaughton, 1972]. By using the similarity of heat, vapor, and momentum transport, these profiles suc- 


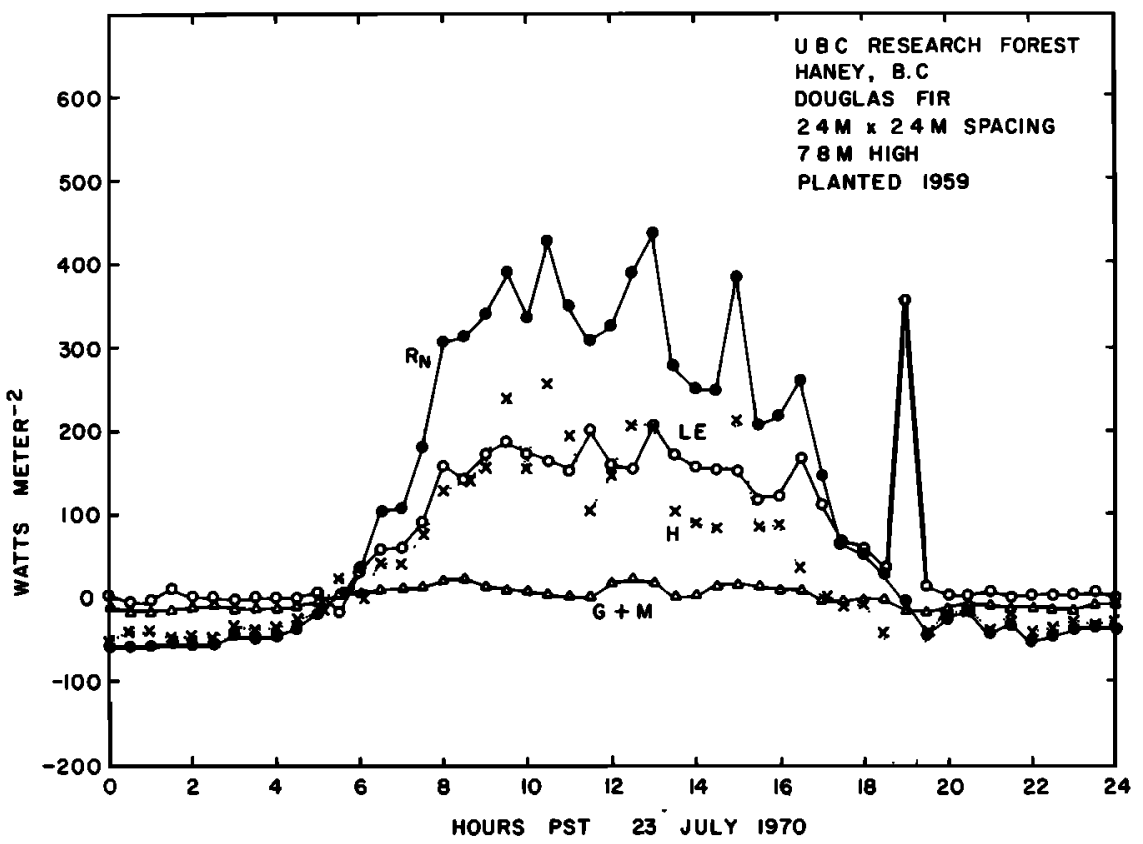

Fig. 1. Energy balance diagram for a day with variable net radiation. The latent heat flux density is largely independent of the short-term changes in net radiation. The Bowen ratio at 1900 PST was -0.97 .

cessfully predicted the diurnal variation of the eddy diffusivity and were used by Black and McNaughton to compute latent heat flux with about $34 \%$ overestimation. Values of the friction velocity and wind speed at 8.6 meters were calculated from the same synthetic profiles and used to calculate $r_{a}$ from (2). These values are probably systematically underestimated by about $30 \%$.

Daytime trends of wind speed and aerodynamic resistance calculated from the synthetic profiles when constant $z_{0}$ and $D$ are assumed are shown for the four sample days in Figure 2. Aerodynamic resistance exhibited a marked diurnal pattern with a definite decrease and increase at about 0600 and 1730 PST, respectively, when reversals in the sensible heat flux occurred. Daytime values of $r_{a}$ usually were between 5.5 and $7.5 \mathrm{sec} \mathrm{m}^{-1}$ and showed less variation than the wind speed. Szeicz et al. [1969] have noted a similar small variation in daytime values of $r_{a}$ in their analysis of wind profiles measured above a 27 -meter-high Norway spruce forest in Germany.

Using (7) to estimate the error in $r$, calculated from (4) due to uncertainty in $r_{a}$ shows that, in a worst-case daytime situation, $r$, derives an uncertainty of $\pm 8 \mathrm{sec} \mathrm{m}^{-1}$ from this source. This uncertainty is small in comparison with the diurnal and day-to-day differences in the calculated values of $r_{\text {, }}$.

Typical daytime $r$, trends are shown in Figure 2. Nighttime and late-afternoon values, when the Bowen ratio was near -1 , were erratic and frequently negative. Daytime trends for each day from July 8 through 13 generally followed the pattern observed for July 10 (Figure $2 b$ ). Of the 13 days following July 13, six had surface resistances notably higher than those for the period, two had notably lower values, and the remainder had similar values. On the six days with higher surface resistances the early-morning values were about $60 \mathrm{sec} \mathrm{m}^{-1}$, as was observed for the days prior to July 13, but increased more rapidly during the day. This behavior is illustrated in Figures $2 c$ and $d$ for July 15 and 18, respectively.

Interpreting this behavior as an increase in stomatal resistance on those days indicates that there was water-stress-induced stomatal closure. The result is unexpected, since there was a plentiful supply of water in the root zone held 

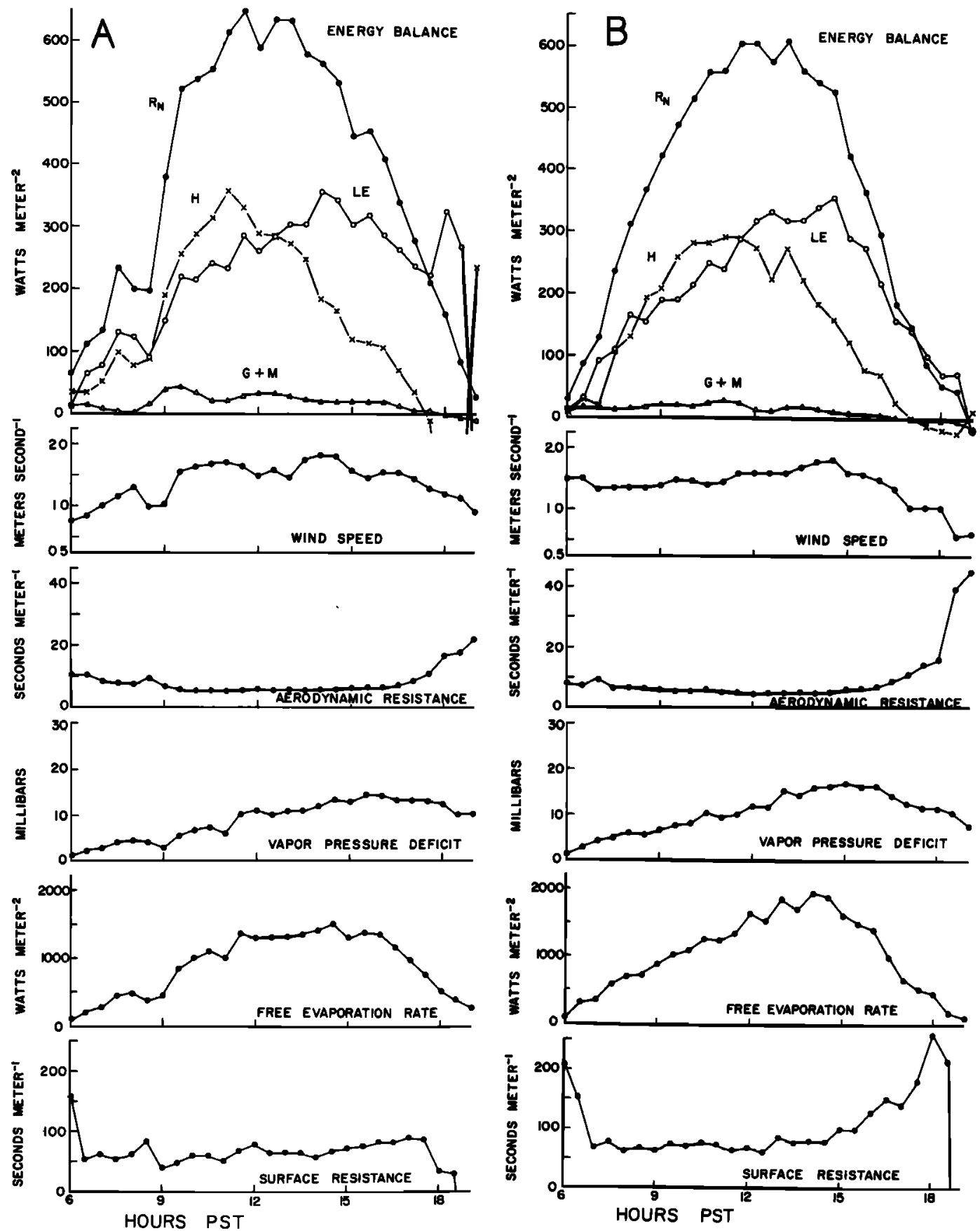

Fig. 2. Daytime trends of meteorological parameters and the derived surface diffusion resistance of a 7.8-meter-high Douglas fir forest at Haney, British Columbia. The free evaporation rate is shown as the equivalent latent heat flux density. Erratic values of the sensible and the latent heat flux and consequently the surface resistance near 1800 PST are due to Bowen ratios near -1 at those times. (a) July 8, 1970. (b) July 10, 1970. (c) July 15, 1970. (d) July $18,1970$. 

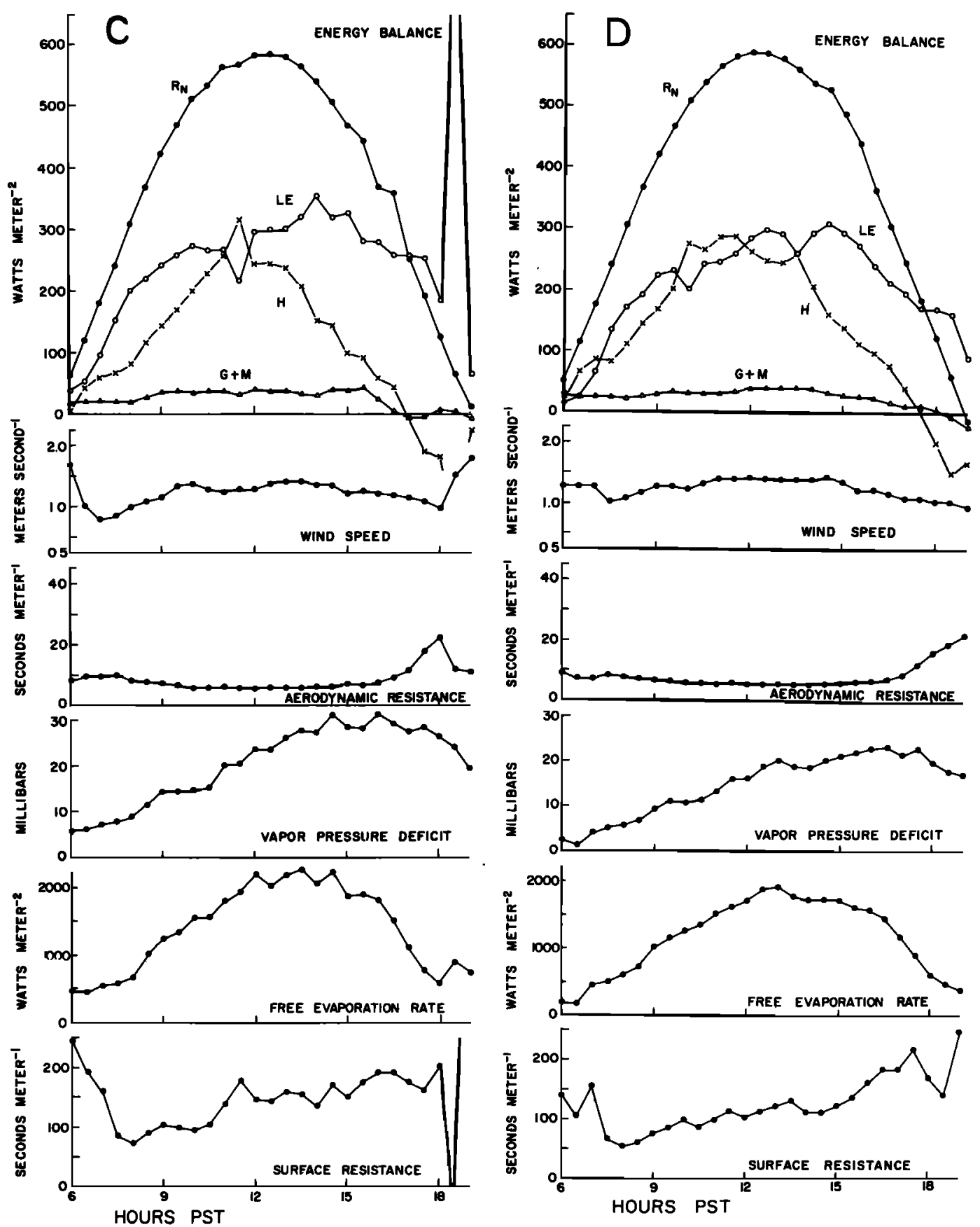

Fig. 2. (continued)

at relatively high soil water matric potentials. Soil water matric potentials at the $60-\mathrm{cm}$ depth are shown for 0600 PST each day in Table 1. The wetting front from the heavy rainfall on
July $25 \mathrm{had}$ not reached $60 \mathrm{~cm}$ at the time of the recording.

On July 21 very light rain fell for about 2 hours, commencing at $0930 \mathrm{PST}$, and the 
TABLE 1. Summary of Daily Evapotranspiration Data from a Douglas Fir Forest at the UBC Research Forest, Haney, British Columbia

\begin{tabular}{|c|c|c|c|c|c|c|c|c|}
\hline $\begin{array}{c}\text { Date, } \\
\text { July } \\
1970\end{array}$ & $\begin{array}{c}E,{ }^{*} \\
\mathrm{~mm}\end{array}$ & $\begin{array}{l}E_{0}{ }^{*} \\
\mathrm{~mm}\end{array}$ & $\begin{array}{l}E_{75}{ }^{*} \\
\mathrm{~mm}\end{array}$ & $\underset{\mathrm{mm}}{[s /(s+\gamma)]\left(R_{N}-G\right),{ }^{*}}$ & $\begin{array}{l}R_{N}{ }^{*} \\
\mathrm{~mm}\end{array}$ & $\begin{array}{l}T, \dagger \\
{ }^{\circ} \mathbf{C}\end{array}$ & $\begin{array}{l}\text { Rain, } \\
\text { mm }\end{array}$ & $\begin{array}{l}-\Psi_{m}, \ddagger \\
\text { bars }\end{array}$ \\
\hline 8 & 4.34 & 19.15 & 4.07 & 4.34 & 6.73 & 18.3 & & 0.053 \\
\hline 9 & 4.39 & 20.70 & 4.15 & 4.15 & 6.46 & 16.4 & & 0.062 \\
\hline 10 & 4.03 & 22.59 & 4.50 & 3.74 & 5.93 & 15.5 & & 0.064 \\
\hline 11 & 4.20 & 23.91 & 4.40 & 4.19 & 6.71 & 15.6 & & 0.069 \\
\hline 12 & 4.15 & 25.27 & 4.26 & 4.10 & 6.51 & 16.3 & & 0.074 \\
\hline 13 & 4.08 & 22.33 & 3.98 & 4.09 & 6.53 & 15.9 & & 0.080 \\
\hline 14 & 4.65 & 26.77 & 5.45 & 4.16 & 6.45 & 18.4 & & 0.089 \\
\hline 15 & 4.80 & 33.04 & 7.66 & 4.22 & 6.29 & 22.0 & & 0.098 \\
\hline 16 & 2.40 & 18.57 & 3.11 & 2.10 & 3.20 & 17.3 & & 0.110 \\
\hline 17 & 3.84 & 18.89 & 3.74 & 4.07 & 6.45 & 15.9 & & 0.119 \\
\hline 18 & 4.29 & 26.64 & 5.88 & 4.13 & 6.33 & 19.9 & & 0.132 \\
\hline 19 & 3.61 & 22.21 & 4.94 & 3.50 & 5.31 & 19.8 & & 0.148 \\
\hline 20 & 3.10 & 13.06 & 2.97 & 2.51 & 3.90 & 16.9 & & 0.168 \\
\hline 21 & 1.46 & 7.29 & 1.16 & 1.01 & 1.47 & 12.0 & 0.25 & 0.189 \\
\hline 22 & 3.18 & 14.52 & 2.89 & 3.05 & 4.99 & 14.2 & & 0.203 \\
\hline 23 & 2.56 & 15.52 & 3.23 & 2.59 & 4.19 & 15.0 & & 0.230 \\
\hline 24 & 1.75 & 9.38 & 1.96 & 1.64 & 2.63 & 13.6 & 0.5 & 0.261 \\
\hline 25 & 1.49 & 1.56 & 0.43 & 1.26 & 2.05 & 12.3 & 33.5 & 0.297 \\
\hline
\end{tabular}

* 24-hour totals expressed as equivalent depths.

$\dagger$ 24-hour arithmetic mean of half hourly temperatures above the forest.

$\$$ Measurement at 60-cm depth in the soil at 0600 PST.

weather station recorded 0.01 in. $(0.25 \mathrm{~mm})$ of precipitation. The rain was almost totally intercepted by the canopy, and the forest floor was not noticeably wetted. Surface resistance values immediately fell to about $15 \mathrm{sec} \mathrm{m}^{-1}$ and remained near this value for $3 \frac{1}{2}$ hours. During this period of lower surface resistances, energy balance results show that $0.31 \mathrm{~mm}$ of water evaporated. The period of low surface resistance, therefore, corresponded to the period during which intercepted water was probably present on the foliage. July 25 was a day of continuous rain, and surface resistance values were close to zero all day.

Elsewhere in the coastal Douglas fir region Phillips [1967] has studied the daily trends of stomatal resistance of a dominant Douglas fir tree in a closed stand at La Grande, Washington. Using a pressure infiltration technique, he found daily trends of stomatal resistance consistent with those shown in Figure 2. Phillips also noted that smaller stomatal resistances were observed on days of lower vapor pressure deficit as indicated by hygrothermograph measurements at ground level. If the surface resistance is simply the stomatal resistance of all the leaves acting in parallel and if a leaf area index of about 10 is assumed for the UBC forest, a typical stomatal resistance for mornings of about $700 \mathrm{sec} \mathrm{m}^{-1}$ is indicated. Phillips' results show $150 \mathrm{sec} \mathrm{m}^{-1}$ as a typical morning value.

As was noted previously, the simple canopy model expressed by (4) should be treated with caution. Nevertheless, it does seem that the day-to-day differences in surface resistance are unlikely to be artifacts of the model, since wind speed and net radiation were quite similar on days when resistances were significantly different, as is illustrated by the sample days in Figure 2. Furthermore, the trends of $r_{s}$ are generally consistent with Phillips' measurements of stomatal resistance made on similar trees.

It seems likely, therefore, that the observed short-term independence of the measured forest evapotranspiration and net radiation is a result of the roughness of the forest canopy and that the meteorological factor most directly controlling forest evapotranspiration is the vapor pressure deficit. This hypothesis should be readily testable by use of the more sophisticated multilayered canopy model of Waggoner et al. [1969], in which aerodynamic resistance above 
the canopy, net radiation, vapor pressure deficit, and stomatal resistance parameters can all be manipulated independently.

Potential evapotranspiration estimates. Since water was plentiful in the root zone throughout the period July 7-25, actual forest evapotranspiration should have been at the potential rate. The estimates of evapotranspiration from the UBC forest can therefore be used to test several approaches to the estimation of potential evapotranspiration.

The formula for the free evaporation rate (1) has two additive terms that can be called for convenience the energy term and the convective term. Accurate determination of $E_{0}$ is relatively easy for low agricultural crops since the energy term predominates, and the aerodynamic resistance can be determined with suffi-. cient accuracy since the convective term is in the nature of a correction. For the UBC forest the convective term was as much as seven times greater than the energy term owing to small $r_{a}$ values, and consequently the uncertainty in $r_{a}$ leads to a probable overestimate in $\boldsymbol{E}_{0}$ of about $25 \%$. Both vapor pressure deficit and $E_{0}$ are presented for the sample days in Figure 2. The free evaporation rate has been expressed as the latent heat flux density equivalent $\left(L E_{0}\right)$, so that the measured evapotranspiration and free evaporation rates can be compared directly.

In spite of the uncertainty in $E_{0}$, a comparison of the measured evapotranspiration rate with the free evaporation rate is instructive. Values of $E$ and $E_{0}$ for the period July 8-25 are given in Table 1. It can be seen that $E_{0}$ is many times greater than $E$ on all days but July 25 . This, plus the difficulty of accurately measuring $r_{a}$ and therefore of calculating $\boldsymbol{E}_{0}$, indicates that $E_{0}$ has little practical significance as a potential evapotranspiration measure for forests.

On July 25, rain fell continuously, commencing at 0130 PST. The canopy was already wet from a light shower at about 1800 PST the previous evening. The assumption of a saturated surface in the derivation of (1) was satisfied. Error in the calculation of $E_{0}$ was small on July 25 since all but two of the half-hour values of the vapor pressure deficit were less than $0.5 \mathrm{mb}$, and the energy term predominated. The net radiometer hemispheres were wet throughout the day, so that the long-wave components of the measurement may have been attenuated. With the prevailing low cloud base, long-wave balance is thought to have been small, and, further, any errors introduced into $R_{N}$ entered almost equally into the calculation of $E$ and $E_{0}$. The close agreement between $E$ and $E_{0}$ suggests that (1) can be used to calculate evaporation from wet forests. However, the agreement is far better than expected in view of the small temperature gradients, and hence the large possible errors in Bowen ratio determinations used to calculate $E$. This result should not be considered definitive.

An alternative approach to the estimation of potential evapotranspiration is to attempt to determine representative values of the surface resistance for various surfaces [Szeicz and Long, 1969] so that these may be used in (4) to calculate evapotranspiration. We have therefore examined our results to see if a single daytime value of $r_{s}$ could be found that would represent the typical behavior of the forest when it was not short of water. Such a value, it was hoped, would represent the forest with the normal number of stomata open to a normal degree for stress-free conditions.

Since the rise in surface resistance was noticed after July 13, only the first six days were used to determine the value. It was found that values of evapotranspiration for the first six days plus three later days could be calculated to within $10 \%$ by rather arbitrarily setting $r_{s}$ equal to $75 \mathrm{sec} \mathrm{m}^{-1}$ in the daytime period from 0700 to 1800 PST and $500 \mathrm{sec} \mathrm{m}^{-1}$ for the remaining hours. Daily values of evapotranspiration calculated by this method, denoted by the symbol $E_{\pi s}$, are plotted against the measured 24-hour totals of evapotranspiration in Figure 3. Two points lie significantly below the line and are for days when rain fell. Seven points fell significantly above the line. As a potential evapotranspiration measure, $E_{\pi \mathrm{s}}$ may have some merit, but on half the days the difference between $E_{7 \bar{s}}$ and $E$ was greater than $10 \%$ and on July 15 was $40 \%$, even though there was a plentiful supply of water in the root zone throughout the period.

Where advected energy is not an important source of energy for evapotranspiration and soil water is adequate, a close relationship between net radiation and daily evapotranspiration is expected. Examination of the data from the UBC forest reveals that daily evapotrans- 


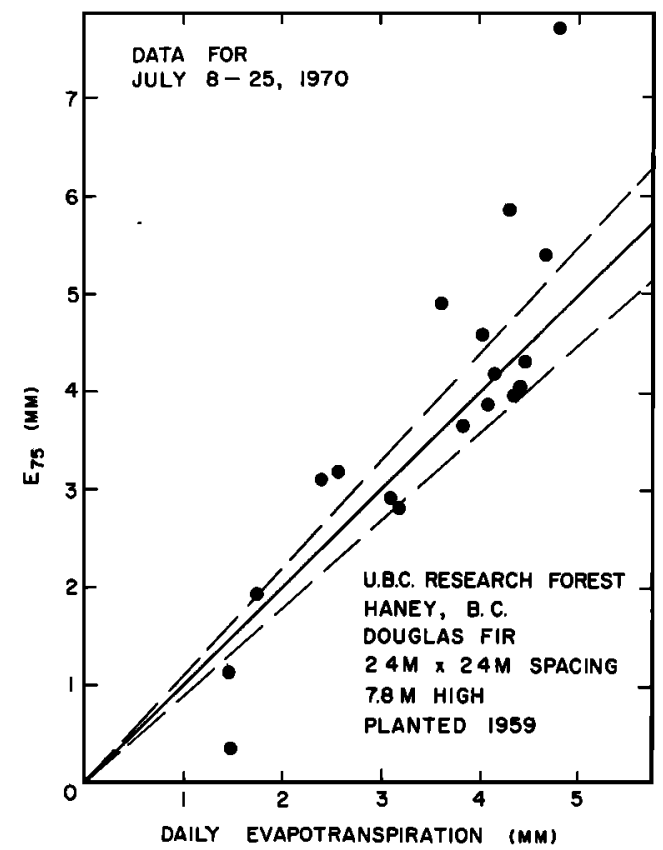

Fig. 3. Comparison of calculated 24-hour evapotranspiration values assuming constant daytime surface resistance of $75 \mathrm{sec} \mathrm{m}^{-1}$ with measured values. Dashed lines represent $10 \%$ deviation from the 1:1 line.

piration and net radiation were highly correlated. Energy used in daily evapotranspiration was generally about two thirds of net radiation.

Before such a correlation can be used with confidence as a basis for estimating evapotranspiration, further work must be done to determine the influence of other factors, such as tree phenology and presence of intercepted water on the canopy, on the partitioning of the available energy between sensible and latent heat fluxes. Examination of the UBC forest data allows us to make some estimate of the importance of interception. In the absence of advection the maximum possible rate of evapotranspiration is given by $\left(R_{N}-G\right)$. With typically small $G$ values for the forest, this equation implies that the maximum possible rate of evaporation of intercepted water after general rain could not be more than $50 \%$ faster than the observed rates.

Perhaps a more realistic estimate of the influence of intercepted water can be obtained by comparing the result from the dry transpiring canopy with a relationship found by Priestley and Taylor [1972]. They have surveyed several experiments over surfaces where surface resistance was expected to be negligibly small and $E_{0}$ was expected to be equal to the actual evaporation rate. They examined both terrestrial and oceanic data from locations where the effects of advection were expected to be negligible. They used the data to determine a coefficient $\alpha$ to satisfy the equation

$$
E=(\alpha / L)[s /(s+\gamma)]\left(R_{N}-G\right)
$$

where the energy flux density terms are here 24-hour integrals with units of equivalent depth in millimeters of water evaporated and $s$ is calculated from the mean surface temperature. The best value of $\alpha$ was found to be 1.26.

Measured evapotranspiration rates from the $\mathrm{UBC}$ forest site plotted against $(1 / L)[s /(s+$ $\gamma)$ ] $\left(R_{N}-G\right)$ are shown in Figure 4 . When July 21 and 25, on which rain fell, are neglected, a value for $\alpha$ of 1.05 is found.

When the possible errors in determining each value of $\alpha$ are considered, these values are not necessarily significantly different. However, it does seem probable that evaporation from the UBC forest, when it is wet, would proceed

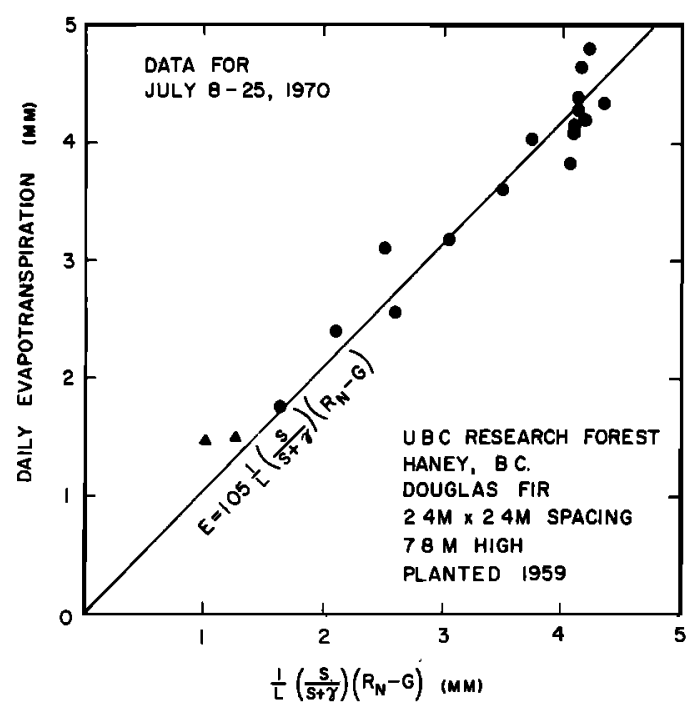

Fig. 4. Measured daily values of evapotranspiration in comparison with $(1 / L)[s /(s+\gamma)]$ $\left(R_{N}-G\right)$. Data for July 21 and July 25, when rain fell, are shown as triangles and have not been used to determine the line of best fit. The available energy $R_{N}-G$ is expressed as an equivalent depth of water evaporated. 
at a rate $20 \%$ faster than the expected evapotranspiration from the same canopy when it is well supplied with water but not wet. On July $25, \alpha$ was 1.18 , which is close to the value found by Priestley and Taylor for wet surfaces and tends to support the validity of this comparison. Data from July 21 are not suitable for use in this comparison since the high value of $a$ for this day $(\alpha=1.45)$ is a result of a clear sky before dawn, and thus the 24-hour radiation total is unrepresentative of the daytime period. During the period when the canopy was wet on this day, $L E$ was about three quarters of $R_{N}$.

An estimate of the importance of interception losses by the forest can now be made. Gross interception loss $I$ is the amount of precipitation onto the forest that is caught by the canopy and reevaporates without reaching the ground. However, because the leaves are wet, transpiration is at the same time suppressed, and not all of the gross interception loss represents a loss in the hydrologic sense. The net interception loss is the difference between gross interception loss and the reduction in transpiration caused by the presence of the intercepted water. From the above result, only $17 \%$ of the gross loss can be considered to be net loss.

Perhaps the best potential evapotranspiration relationship that can be suggested from the present study is

$P=(1.05 / L)[s /(s+\gamma)]\left(R_{N}-G\right)+0.17 I$

where the energy flux density terms have been integrated over 24-hour periods, as in (9).

\section{Conclusions}

Measurements of evapotranspiration made at the UBC Research Forest showed that peak evapotranspiration rates occurred $2-3$ hours after solar noon and that evapotranspiration was not strongly affected by short-term changes in net radiation. On the basis of a simplified analysis using Monteith's combination canopy model it is hypothesized that this is a direct effect of the large canopy roughness and that vapor pressure deficit is the dominant meteorological factor directly controlling forest evapotranspiration.

On a daily basis, measurements of net radiation and evapotranspiration were highly corre- lated. By comparing the UBC forest results with a relationship developed by Priestley and Taylor to predict evaporation from wet surfaces, it is tentatively inferred that intercepted water evaporates $20 \%$ more rapidly than transpired water and that therefore only $17 \%$ of gross interception losses at the UBC forest are to be considered as net interception losses.

\section{Notation}

$D$, zero plane displacement, meters;

$E$, evapotranspiration rate, $\mathrm{kg} \mathrm{m}^{-2} \sec ^{-1}$;

$E_{0}$, free evaporation rate, $\mathrm{kg} \mathrm{m}^{-2} \mathrm{sec}^{-1}$;

$E_{75}$, total 24-hour evapotranspiration assuming daytime $r_{s}=75 \mathrm{sec} \mathrm{m}^{-1}, \mathrm{~mm}$;

$G$, soil heat flux density, w $\mathrm{m}^{-2}$;

$H$, sensible heat flux density, w $\mathbf{m}^{-2}$;

$I$, gross interception loss, mm;

$L$, latent heat of vaporization of water, joules $\mathbf{k g}^{-\mathbf{1}}$;

$M$, rate of heat storage in the canopy volume on an area basis, $w \mathbf{m}^{-2}$;

$P$, potential evapotranspiration, $\mathrm{mm}$;

$R_{N}$, net radiation flux density, $\mathrm{w} \mathrm{m}^{-2}$;

$T$, temperature, ${ }^{\circ} \mathrm{C}$;

$c_{p}$ specific heat of moist air, joules $\mathrm{kg}^{-1} \mathrm{~K}^{-1}$;

$e_{0}$, water vapor pressure at the canopy surface, $\mathrm{mb}$;

$e_{0}{ }^{*}$, saturation water vapor pressure at the canopy surface temperature, $\mathrm{mb}$;

$e_{z}$, water vapor pressure at height $z, \mathrm{mb}$;

$e_{z}^{*}$, saturation water vapor pressure at height $z$, $\mathrm{mb}$;

$r_{a}$, aerodynamic diffusion resistance at height $z$ (assumed equal to $u_{z} / u_{*}^{2}$ ), sec $\mathrm{m}^{-1}$;

$r_{\text {, }}$ surface diffusion resistance, sec $\mathrm{m}^{-1}$;

$s$ slope of the saturation water vapor pressure curve, $\mathbf{m b ~ K}^{-1}$;

$u_{\varepsilon}$, wind velocity at height $z, \mathrm{~m} \mathrm{sec}^{-1}$;

$u_{*}$, friction velocity, $\mathrm{m} \mathrm{sec}^{-1}$;

$z$, height above soil surface, meters;

$z_{0}$, roughness length, meters;

$\Psi_{m}$, soil water matric potential, bars;

$\alpha$, empirical coefficient;

$\beta$, Bowen ratio, identically equal to $H / L E$;

$\gamma$, psychrometric constant, equal to $0.66 \mathrm{mb}$ $\mathbf{K}^{-1}$;

$\rho$, density of moist air, $\mathrm{kg} \mathrm{m}^{-3}$.

Acknowledgments. We would like to thank Mr. John Walters, Director of the UBC Research Forest, for his cooperation in the measurement phase of this research. This research was supported by grants from the National Research Council of Canada and the Canada Department of the Environment (NACWRR).

\section{REFERENCES}

Black, T. A., and K. G. MeNaughton, Psychrometric apparatus for Bowen-ratio determination over forests, Boundary Layer Meteorol., 2, 246254, 1971. 
Black, T. A., and K. G. McNaughton, Average Bowen-ratio methods of calculating evapotranspiration applied to a Douglas-fir forest, Boundary Layer Meteorol., 2, 466-475, 1972.

Businger, J. A., Some remarks on Penman's equation for evapotranspiration, Neth. J. Agr. Sci., 4, 77-80, 1956.

Cowan, I. R., Estimation of evaporation using meteorological data, in Land Evaluation Papers of CSIRO Symposium Organized in Cooperation with UNESCO, edited by G. A. Steward, pp. 291-311, Macmillan, New York, 1968.

Federer, C. A., Spatial variation of net radiation albedo and surface temperature of forests, $J$. Appl. Meteorol., 7, 789-794, 1968.

Fritschen, I. J., and P. Doraiswamy, Dew: An addition to the hydrologic balance of Douglas fir, Water Resour. Res., 9(4), 891-894, 1973.

Gay, L. W., Energy flux studies in a coniferous forest ecosystem, in Proceedings-Research on Coniferous Forest Ecosystems-A Symposium, edited by J. F. Franklin, L. J. Dempster, and R. H. Waring, pp. 243-253, Pacific and North-

- west Forest and Range Experimental Station, Portland, Oreg., 1972.

Hinckley, T. M., and D. R. M. Scott, Estimates of water loss and its relation to environmental parameters in Douglas-fir saplings, Ecology, 52, 520-524, 1971.

Ladefoged, $K$., Transpiration of forest trees in closed stands, Physiol. Plant., 16, 378-414, 1963.

Monteith, J. I., Evaporation and environment, Symp. Soc. Exp. Biol., 19, 205-234, 1965.

Parker, J., The cut-leaf method and estimations of diurnal trends in transpiration from different heights and sides of an oak and a pine, Bot. Gaz. Chicago, 199, 93-101, 1957.

Penman, H. L., Natural evaporation from open water, bare soil and grass, Proc. Roy. Soc. London, Ser. A, 193, 120-145, 1948.

Phillip, J. R., Comments on paper by Monteith, in Environmental Control of Plant Growth, edited by L. T. Evans, p. 111, Academic, New York, 1963.

Phillip, J. R., Plant water relations: Some physical aspects, Ann. Rev. Plant Physiol., 17, 245268,1966 .
Phillips, R. A., Stomatal characteristics throughout a tree crown, M.F. thesis, 67 pp., Univ. of Wash., Seattle, 1967.

Priestley, C. H. B., and R. J. Taylor, On the assessment of surface heat flux and evaporation using large-scale parameters, Mon. Weather Rec., 100, 81-92, 1972.

Rutter, A. J., Studies on the water relations on Pinus Sylvestries in plantation conditions, $J$. Appl. Ecol., 3, 393-405, 1966.

Rutter, A. J., An analysis of evaporation from a stand of Scots pine, in International Symposium on Forest Hydrology, edited by W. E. Sopper and $H$. W. Lull, pp. 403-417, Pergamon, New York, 1967.

Stewart, J. B., and A. S. Thom, Energy budgets in pine forest, Quart. J. Roy. Meteorol. Soc., 99, 154-170, 1973.

Szeicz, G., and I. F. Long, Surface resistance of crop canopies, Water Resour. Res., 6(3), 622633, 1969.

Szeicz, G., G. Endrodi, and S. Tajchman, Aerodynamic and surface factors in evaporation, Water Resour. Res., 5(2), 380-394, 1969.

Tanner, C. B., Energy relations in plant communities, in Environmental Control of Plant Growth, edited by L. T. Evans, pp. 141-148, Academic, New York, 1963.

Tanner, C. B., and M. Fuchs, Evaporation from unsaturated surfaces, J. Geophys. Res., 73, 1299-1303, 1968.

Tanner, C. B., and W. L. Pelton, Potential evapotranspiration by the approximate energy balance method of Penman, J. Geophys. Res., $65,3391-3413,1960$.

Thom, A. S., Momentum, mass and heat exchange of vegetation, Quart. J. Roy. Meterol. Soc., 98, 124-134, 1972.

Van Bavel, C. H. M., Potential evaporation: The combination concept and its experimental verification, Water Resour. Res., 2(3), 455-467, 1966.

Waggoner, P. E., G. M. Furnival, and W. E. Reifsnyder, Simulation of the microclimate in a forest, Forest Sci., 15, 37-45, 1969.

(Received January 3, 1973; revised July $27,1973$. ) 